\title{
Correlation between Hardness, Structure and Electrochemical Performance of an AlZnMnMg Alloy
}

\author{
S. Valdez Rodríguez ${ }^{1}$, B. Campillo Illanes ${ }^{1}$, J. J. Alberto Islas ${ }^{2}$ \\ ${ }^{1}$ Instituto de Ciencias Físicas, Universidad Nacional Autónoma de México, Morelos, México \\ ${ }^{2}$ Instituto de Investigaciones en Materiales, Universidad Nacional Autónoma de México, México City, México \\ Email: svaldez@fis.unam.mx
}

Received June 7, 2012; revised July 9, 2012; accepted July 19, 2012

\begin{abstract}
In this work the structural changes induced by aged treatment have shown a connection with differences of hardness and electrochemical performance. Al-base alloys have been investigated by means of Vickers hardness, X-ray diffraction, scanning electron and short-term electrochemical test. X-ray diffraction result reveals the formation of $(\mathrm{MgZn})_{49} \mathrm{Al}_{32}$ phase for two conditions, the first one is when the magnesium content is upper to $5.49 \%$ in as-cast condition and the second one after the thermal treatment carried out at $450^{\circ} \mathrm{C}$ for $5 \mathrm{~h}$. In addition, the hardness and electrochemical performance has been influenced by the presence and quantity of the $(\mathrm{MgZn})_{49} \mathrm{Al}_{32}$ phase. The addition of magnesium alloying modifies the microstructure, increases the content of $(\mathrm{MgZn})_{49} \mathrm{Al}_{32}$ phase and provides a localized corrosion which conduced to the breakdown of the oxide film $\left(\gamma-\mathrm{Al}_{2} \mathrm{O}_{3}\right)$ formed on the $\mathrm{Al}$ alloy surface.
\end{abstract}

Keywords: AlZnMnMg Alloy; Hardness; Structure; Electrochemical Performance

\section{Introduction}

Combined with total life-cycle cost the alloy produced from $\mathrm{Al}, \mathrm{Zn}, \mathrm{Mg}$ metallic elements basically are considered an effective substitute for a number of ferrous and nonferrous alloys [1]. These kinds of alloys could be considered lightweight and cost-effective materials. The AlZnMg alloys combine their ductility and conformability with low-density, excellent castability, high specific strength and high hardness [2]. The characteristic of AlZnMg alloys and almost all aluminum alloys is the recyclable after serving in the original purpose. In addition, this alloy has been considered for service as galvanic anode [3]. In name only, anode could be applied to any metallic structure in contact with a bulk electrolyte. The selection is based on evidence that aluminum alloys exhibit an anodic dissolution process, low active electrode potential $(-950$ to $-1200 \mathrm{mV})$ and high theoretical current capacity [4]. In fact, magnesium is the most important alloying element for good performance as sacrificial anode. To prevent passivation of aluminum through developing a non-conducting film on their surfaces, the activation has been previously obtained with elements such as indium, tin, mercury and bismuth. These alloying elements are present in solid solution or as segregated phase [5] and with the precipitation of intermetallic phases formed after heat treatment [6]. With a special thermal treatment [7] has been also improved the strong age-hardening given to the system their unique combination of lightweight and high mechanical properties [8]. The investigation of precipitation process in Al-base alloys indicates that several transformation sequences may occur in these materials during ageing [9]. For the case in this work, heat treatment relies on the fine precipitation of the $(\mathrm{MgZn})_{49} \mathrm{Al}_{32}$ and $\mathrm{MgZn}_{2}$ phases. The formation of solute-rich precipitates begins from the supersaturated solid solution (SSS) $\alpha$-aluminum matrix. The stable hardening phase strains the crystallographic planes of the $\mathrm{Al}$ matrix. Hardness is one of the mechanical properties, which have been highlighted with the microstructure on metallic alloys [10].

However, the link between hardness and electrochemical efficiency are critically dependent on both the composition and the microstructure. This one is developed during casting, thermomechanical processing and heat treatment [7]. It is well-known that the microstructure is essential for the properties of alloys. For the case of corrosion particularly the influence of dendrite arm spacing has become related with mechanical properties. Dendrite arm spacing is principal changed by cooling rate during solidification process. In this work as an alternative of study, it has been considered the ability of magnesium as third alloy component. Magnesium is the most active or anodic metal in the galvanic series and magnesium alloy component is always the active anode if it is in contact with other metals [11]. 
Even though the relationship between microstructure plus electrochemical dissolution and hardness of AlZnMn$\mathrm{xMg}$ alloys has been few studied [12,13]. With all this in mind, the present study will deal with the microstructural evolution. Microstructure will be modified by different atomic combination of magnesium alloying in as-cast condition firstly. Aging thermal treatment was done as the second condition to transform the microstructure.

The present investigation is concentrating on studying the effects of magnesium addition on the microstructure in as-cast and after ageing treatment. Likewise, we correlated it with hardness and electrochemical efficiency. The aim of the present study was to understand better the role played by magnesium on the $(\mathrm{MgZn})_{49} \mathrm{Al}_{32}$ particles distribution which produces the activation anodic process related with the galvanic efficiency and the hardness for the AlZnMn-xMg alloy. This includes microstructural examination, electrochemical efficiency calculations and hardness tests. Microstructure was studied using Scanning Electron Microscopy with an Energy-Dispersive Xray spectroscopy analysis and X-ray diffraction. The electrochemical behavior was studied by open-circuit potential measurements. We found that effectively the thermal treatment and high magnesium content are the principal factors for structure changes and also for the electrochemical efficiency and hardness results of the AlZnMn-xMg alloys. The electrochemical test reveals the susceptibility of AlZnMn-xMg alloy with the artificial ageing and the presence and quantity of the $(\mathrm{MgZn})_{49} \mathrm{Al}_{32}$ phase.

\section{Experimental Procedure}

\subsection{Synthesis of AlZnMn-xMg Alloys and Thermal Treatment}

The alloy was processed by stoichiometrically mixing pieces of commercially available elemental $\mathrm{Al}, \mathrm{Zn}$ and $\mathrm{Mg}$ (ingots $99.8 \%$ ). The alloy was prepared by melting $\mathrm{Al}\left(660^{\circ} \mathrm{C}\right), \mathrm{Zn}\left(420^{\circ} \mathrm{C}\right)$ and $\mathrm{Mg}\left(650^{\circ} \mathrm{C}\right)$ ingot pieces in a high alumina crucible, kept in a vacuum induction furnace. To prevent passivation of aluminum alloy, alloying with eight different compositions of $\mathrm{Mg}$ were considered. In addition, a careful control of the concentrations of manganese as trace impurities can be required.

The molten alloy reached at $700^{\circ} \mathrm{C}$ above the liquidus temperature. A constant flux of argon has been used to avoid the contact with the environment and the oxidation of elements. However, in order to compensate some oxidation losses during the pour, $3 \mathrm{wt} \% \mathrm{Al}$ and $7 \mathrm{wt} \% \mathrm{Zn}$ were taken in excess to the required amount of these constituents. The liquid bath was stirred for 10 minutes in order to obtain a uniform distribution of $\mathrm{Zn}$ and $\mathrm{Mg}$. The AlZnMn-xMg melt was conventionally poured into a steel mold to form ingot of $20 \mathrm{~mm} \times 50 \mathrm{~mm} \times 70 \mathrm{~mm}$.
The ingot resultant was machined to eliminate the structure formed by direct contact with the mold wall. The first liquid alloy in contact with mold wall possesses one of the most dominant microstructures, produced in cast form, the wall-equiaxed structure.

In order to know the chemical composition and distribution of the constituent phases as main factors responsible for the corrosion behavior the Table 1 shows the nominal chemical composition of AlZnMn-xMg alloys, obtained by optical emission spectroscopy, using an SPECTROLAB spectrometer Model X8-WINDOWS LAX with 15 analytical channels, which operates under Microsoft Windows environment. These results are the average of five analyses in different regions of the specimens.

\subsection{Thermal Treatment}

With the purpose of investigate the effect of magnesium and heat treatment on the microstructure of the eight AlZnMn-xMg alloys, samples of $100 \mathrm{~g}$, were cut from the cast ingot. These samples were heating treated at $450^{\circ} \mathrm{C}$ for $5 \mathrm{~h}$, allowing that all solute atoms from each soluble phase enrich the solid solution until the quenched. The quenched was carried out in water at room temperature to development of supersaturation. The homogenized samples were then artificially aged at $400^{\circ} \mathrm{C}$ for $1 \mathrm{~h}$, in order to start the precipitation process, characterized by increasing solubility with increasing temperature.

Homogenized process is sensitive to the selected trace elements and microalloying elements, which can change the process and/or kinetics of precipitation in many hardenable alloys by ageing [14]. Frequently the aging heat treatment involves the formation of finely dispersed precipitates from the supersaturated solid solutions in

Table 1. Chemical composition of AlZnMn-xMg alloy given in $w t \%$.

\begin{tabular}{cccc}
\hline \multirow{2}{*}{ Metallic alloy } & \multicolumn{3}{c}{ Chemical elements (wt\%) } \\
\cline { 2 - 4 } & $\mathrm{Mg}$ & $\mathrm{Zn}$ & $\mathrm{Mn}$ \\
\hline Mg-1 & 3.96 & 5.36 & 0.3189 \\
Mg-2 & 4.89 & 5.35 & 0.3125 \\
Mg-3 & 5.49 & 5.32 & 0.3053 \\
Mg-4 & 6.55 & 5.32 & 0.2320 \\
Mg-5 & 7.33 & 5.30 & 0.2931 \\
Mg-6 & 8.65 & 5.29 & 0.2877 \\
Mg-7 & 9.58 & 5.29 & 0.2851 \\
Mg-8 & 11.53 & 5.31 & 0.2178 \\
\hline
\end{tabular}

a: the alloys are balanced with aluminium. Trace elements are in the range of $0.1281625 \pm 0.01512621$. 
order to increase the hardening/strengthening in the alloy system

\subsection{Metallographic Analysis}

The as-cast and aged samples were sectioned longitudenally at mid-width using a band saw. Just one side has been prepared for microstructural characterization by the standard technique. It begun through the grinding with metallographic paper of $\mathrm{SiC}$ up to \#1000, and mechanical polishing with 0.5 and $0.05 \mu \mathrm{m}$ alumina powder. Based on the chemical etching is controlled by the electrolytic action between surface areas at different potentials, the surface alloys was by etching in Keller's reagent [15]. The Keller reagent contained $5 \mathrm{ml}$ of $\mathrm{HNO}_{3}, 3$ $\mathrm{ml}$ of $\mathrm{HCl}, 2 \mathrm{ml}$ of $\mathrm{HF}$, and $190 \mathrm{ml}$ of $\mathrm{H}_{2} \mathrm{O}$; the etch was done at room temperature for 15 secs.

\subsection{Morphological Characterization}

Structural investigations were carried out with a Siemens D5000 X-ray diffractometer (XRD) with a power of 40 $\mathrm{kV}$ accelerating voltage $\mathrm{x} 30 \mathrm{~mA}$ current, using $\mathrm{Cu}$ tube of $\mathrm{K} \alpha$ line radiation: $\lambda=0.15406 \mathrm{~nm}$ and a diffracting beam graphic monochrometer. The XRD patterns were recorded in the $2 \theta$ range of $30^{\circ}-90^{\circ}$ (step size $0.02^{\circ}$, time per step $0.6 \mathrm{~s}$ ) and the evaluation of the diffractograms was made by DIFRACT/AC software.

The AlZnMn-xMg microstructures were observed by Olympus PM-G3 optic microscopy and a Stereoscan 440 scanning electron microscope (SEM) using backscattered electron imaging (SEM) operated at $20 \mathrm{kV}$. SEM combined with energy dispersive X-ray spectroscopy (EDS) OXFORD Isis 300 was used to analyze microstructural modifications as well as to identify the elemental composition of the phases formed.

\subsection{Mechanical Testing}

In order to observe the AlZnMn-xMg alloy's ability to resist plastic deformation from a standard source the Vickers hardness was measured. The measurement was done with a microhardness tester INSTRON model 210013. Values were obtained on the cross-sections of the samples using a load of $2 \mathrm{~N}$ for $10 \mathrm{~s}$ and at least 10 impressions were recorded of each sample. The resulting hardness reading depends on the load and the area of the permanent pyramid impression. Hardness values were averaging excluding the maximum and the minimum values and the experimental error was estimated.

\subsection{Performance Evaluation}

In order to know how many ampere-hours of protective current will be available for each unit-weight of Al$\mathrm{ZnMn}-\mathrm{xMg}$ alloys, the galvanic performances were eva- luated by a short-term electrochemical test [16]. The working electrodes, also called anodes in an oxidation reaction with $10 \mathrm{~mm}^{2}$ width $\times 50 \mathrm{~mm}$ length, were prepared from AlZnMn-xMg ingots of as-cast and aged condition. All the specimens were polished with 1200 emery paper, then degrease in acetone and washed thoroughly in double distilled water. The working electrode used for each test was mounted in a specially designed electrochemical cell using the three-electrode system and was connected electrochemically to a galvanostat DC current source. A saturated calomel electrode (SCE, $\mathrm{E}=+0.242 \mathrm{~V}$ saturated) was the reference electrode, is used as half-cell. The reference electrode controls the working electrode potential and is a reference from the potentials measured. An auxiliary electrode, from electrochemically inert platinum wire, was used as counter electrode. It functions as cathode (in a half cell) and passes all the current needed to balance the reaction at the working electrode. A sheet of carbon steel served as the cathode. While, for the electrolytic test solution was used synthetic sea water. This solution was prepared with sodium chloride analytical grade reagent and distilled water with an initial $\mathrm{pH}$ of 8.3 according to ASTM D1141 [17].

The test anode and cathode were both galvanically coupled together at different current density levels $(0.4$, $1.5,4.0)$ and immersed in the electrolytic solution for 3 days. The anodic current density, $\mathrm{mA} / \mathrm{cm}^{2}$ was applied during a 24-hour period. The samples were taken out and were cleaned by ASTM G 31 standard practice. The anodes were then rinsed with distilled water, dried by blowing hot air and weighed in order to obtain their weight loss. The weight of the AlZnMn-xMg was measured before and after the immersion. From the actual weight loss measured, the capacity and theoretical current or total charge to be produced by the alloy could be calculated. The anode efficiency $(\eta)$ was calculated by the actual ampere hours delivered by AlZnMg-xMg alloys between the theoretical amperes hours calculated from weight loss of AlZnMn-xMg alloys.

\section{Results and Discussion}

\subsection{X-Ray Diffraction}

The qualitative analysis of diffraction pattern in Figure 1 belongs to as-cast and ageing condition from the Al$\mathrm{ZnMn}-\mathrm{xMg}$ alloys. The determination of atomic conformation is in an effort to relate the composition alloys with electrochemical degradation and also the anodic efficiency.

The X-rays enables record of what happens to an AlZnMn-xMg material's crystal structure through the process of casting and heating samples. The Figures 1(a) and (b), shows that the alloys in as-cast and aged condition 


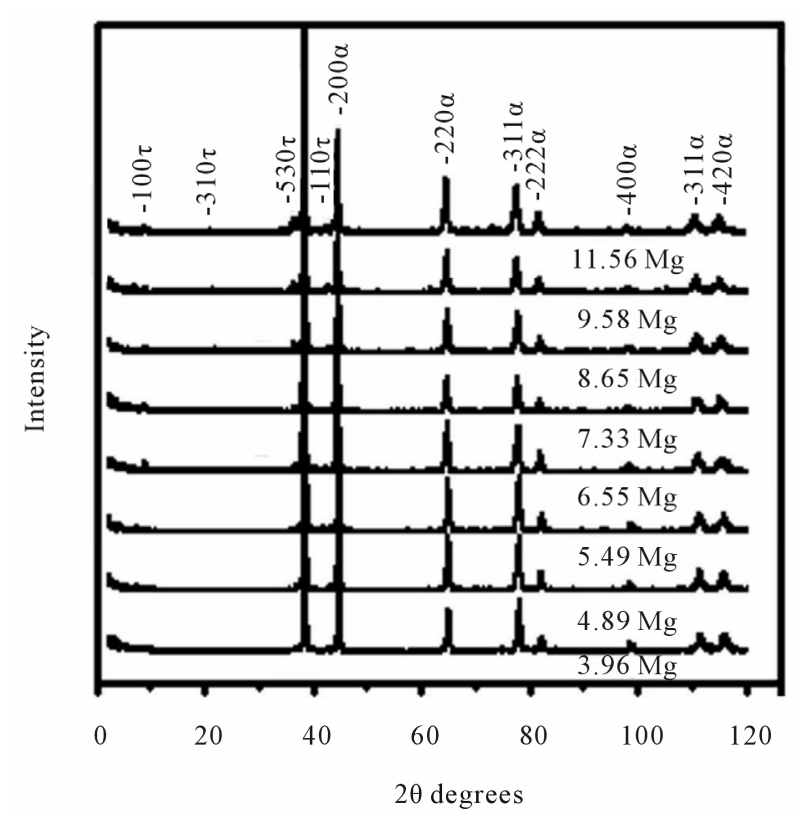

(a)

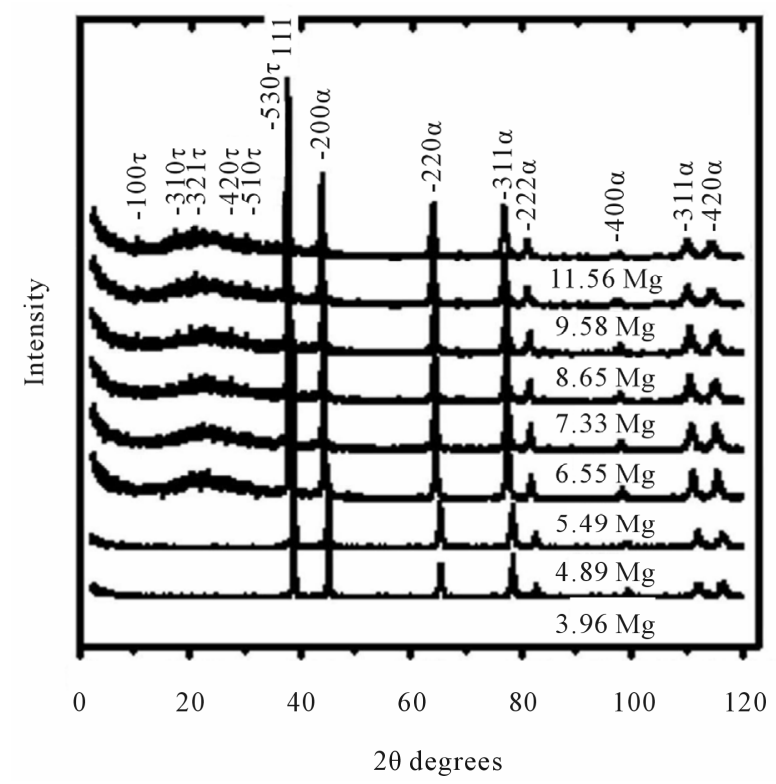

(b)

Figure 1. X-ray diffractograms of the AlZnMn-xMg alloy in as-cast (Figure 1(a)) and aging (Figure 1(b)) showing the presence of the main lines of diffraction $\tau$-(MgZn) ${ }_{49} \mathrm{Al}_{32}$ and $\alpha$-Al peaks with eight different $\mathrm{Mg}$ content.

are composed of $\alpha$-Al solid solution and $(\mathrm{MgZn})_{49} \mathrm{Al}_{32}$ phase, also called precipitates of $\tau$-phase particles. These two phases appears when the Mg addition is up to $5.49 \%$ $\mathrm{Mg}$. The microscopy scanning examination provided additional confirmation of these two phases. The first one phase, is a simple face-centered-cubic (fcc) of $\alpha$-Al solid solution rich in aluminum with an estimated lattice parameter $a=0.4049 \mathrm{~nm}$. The second crystalline phase, is a body-centered cubic (bcc) of $(\mathrm{MgZn})_{49} \mathrm{Al}_{32}$. This phase is also called $\tau-\mathrm{Al}_{2} \mathrm{Mg}_{3} \mathrm{Zn}_{3}$ with lattice parameter $a=0.1416$ $\pm 0.03 \mathrm{~nm}$, Pearson symbol cI 162 and space group Im-3 (No. 204) which is based on a periodic arrangement of icosahedral Berman clusters [18].

Furthermore the presence of $\alpha$-Al solid solution and $(\mathrm{MgZn})_{49} \mathrm{Al}_{32}$ phases are according to the ternary phase diagram [19] merely when the magnesium content is upper to $4.89 \%$ at. For the case of less atomic concentration in magnesium, the intermediate $\tau$-phase magnesiumrich $\left(\mathrm{Mg}_{2} \mathrm{Al}_{3}\right.$ or $\left.\mathrm{Mg}_{5} \mathrm{Al}_{8}\right)$ with cubic cell $\mathrm{a}=2.8239 \mathrm{~nm}$, space group Fd-3m was not detected. Even though the magnesium crystal structure is hexagonal close-packed (hcp) like zinc element, the incorporation of magnesium atoms into the AlZn alloy is entrapped in $\alpha$-Al solid solution. The magnesium rich phase reduces the mechanical properties of castings [8], and has been treated as an unwanted microstructural component for our AlZnMn-xMg alloys.

In addition, the X-ray inspection is unable to distinguish one phase precipitation as can we deduce from the Figure 1(a). This precipitation is suggested by the progressive shifting of diffraction peaks (530) and (100) for the X-ray diffraction. These peaks belongs to

$(\mathrm{MgZn})_{49} \mathrm{Al}_{32}$ phase. The shifting of diffraction is from $2 \theta$ angles of $36.71^{\circ}-35.3^{\circ}$ and $8.80^{\circ}-6.58^{\circ}$ respectively and formed up to $7.33 \% \mathrm{Mg}$ content. The magnesium content is 1.38 times more than the atomic percentage of zinc which one is nearly constant for all the alloys.

$\mathrm{X}$-ray diffractometry follows the structural changes of AlZnMn-xMg alloys produced by casting process and the alloys with an age thermal treatment. The X-ray diffractograms for samples in as-cast and aged conditions, show that $(\mathrm{MgZn})_{49} \mathrm{Al}_{32}$ phase precipitates are formed in our alloys with high $\mathrm{Mg}$ addition. But there are few reflections of the $(\mathrm{MgZn})_{49} \mathrm{Al}_{32}$ phase precipitates for samples with low Mg as can be shown in Figure 1(a). These observations demonstrate that the formation of the $(\mathrm{MgZn})_{49} \mathrm{Al}_{32}$ phase particles was promoted through the high $\mathrm{Mg}$ addition plus the aging treatment condition. Previously, it has been assumed the fact that 7000 series aluminium alloys has a strong trend for preferential precipitation during the subsequent aging process [8].

With the X-ray diffraction measurement, we found the atomic-structure differences between the two phases in AlZnMn-xMg alloys. But it is apparent also from inspection of Figure 1(a) that the relative intensities for the (111) reflection of the $\alpha$-Al (which is a rich-aluminum solid solution with crystalline structure fcc) is much higher than the other peaks. This higher relative intensity indicates the presence of a texture which was developed during the casting operation. It should be mentioned that the XRD intensities are influenced too by the phase content, the crystallite size, lattice strain and degree of crys- 
tallinity [20].

During the heat treatment an atomic reordering of the aluminum matrix exists towards a preferential direction of the planes (220) and (311) as it can be observed in Figure 1(b). The variations in intensity and small displacements of the diffraction angle have their origins from the variations in composition of the alloy probably due to the formation of a supersaturated solid solution enriched by solute atoms like magnesium and zinc. These are the primary elements of alloy, also called second elements associated with a metal to form an alloy.

\subsection{Microstructure Characterization}

The first results showed that the $(\mathrm{MgZn})_{49} \mathrm{Al}_{32}$ phases, are formed by two routes, a first one route as product of the solidification process when the $\mathrm{Mg}$ addition is up $5.49 \% \mathrm{Mg}$. And the second route by the aging precipitation process in the composition range of $7.33 \%$ to $11.53 \%$ at.Mg. The other phase in the Al-alloys under study was the $\alpha-\mathrm{Al}$, which is formed through the solidification route mainly. All the alloys contain $\alpha$-Al with a dendritic structure developed by the combination of thermal and constitutional undercooling. It is well-known that a solidification structure depends strongly on the solidification conditions. The representative microstructure can be observed from the Figures 2(a) and (b) from as-cast condition. These two figures reveal the presence of equiaxed morphology structure. In four of the AlZnMnMg alloys with a composition from $7.33 \%$ to $11.53 \%$ at.Mg, the primary solidification for the $\alpha$-Al solid solution is followed by the eutectic solidification of $\alpha+\tau$ $(\mathrm{MgZn})_{49} \mathrm{Al}_{32}$ phase, these phase can be observed preferentially in Figure 2(b) which corresponds to phase with white color.

It has been reported [2] that the lamellar eutectic structure is derived from the decomposition of the $\alpha^{\prime}$ phase by the following cellular reaction at $488.85^{\circ} \mathrm{C}$

$$
\alpha^{\prime} . \rightarrow \alpha-\mathrm{Al}+(\mathrm{MgZn})_{49} \mathrm{Al}_{32}
$$

The stable phase $(\mathrm{MgZn})_{49} \mathrm{Al}_{32}$ was observed homogeneously dispersed on the Al-matrix with a geometry of rods. The precipitates in Figure 3(a) were observed in aged samples firstly. The heat treatment and high content in $\mathrm{Mg}$ addition caused an increase of volume fraction of $(\mathrm{MgZn})_{49} \mathrm{Al}_{32}$ precipitates.

The microstructure of AlZnMn-xMg alloys observed in as-cast condition was modified with heat treatment. It can be observed from the Figure 3(a) that dendritic structure is broken down and show a quasi-binary eutectic mixture. This apparent eutectic structure are formed by $\mathrm{Al}$ and $(\mathrm{MgZn})_{49} \mathrm{Al}_{32}$ which was always observed along the grain boundaries of the primary $\alpha$-Al matrix in aging condition alloy. In the eutectic region the light
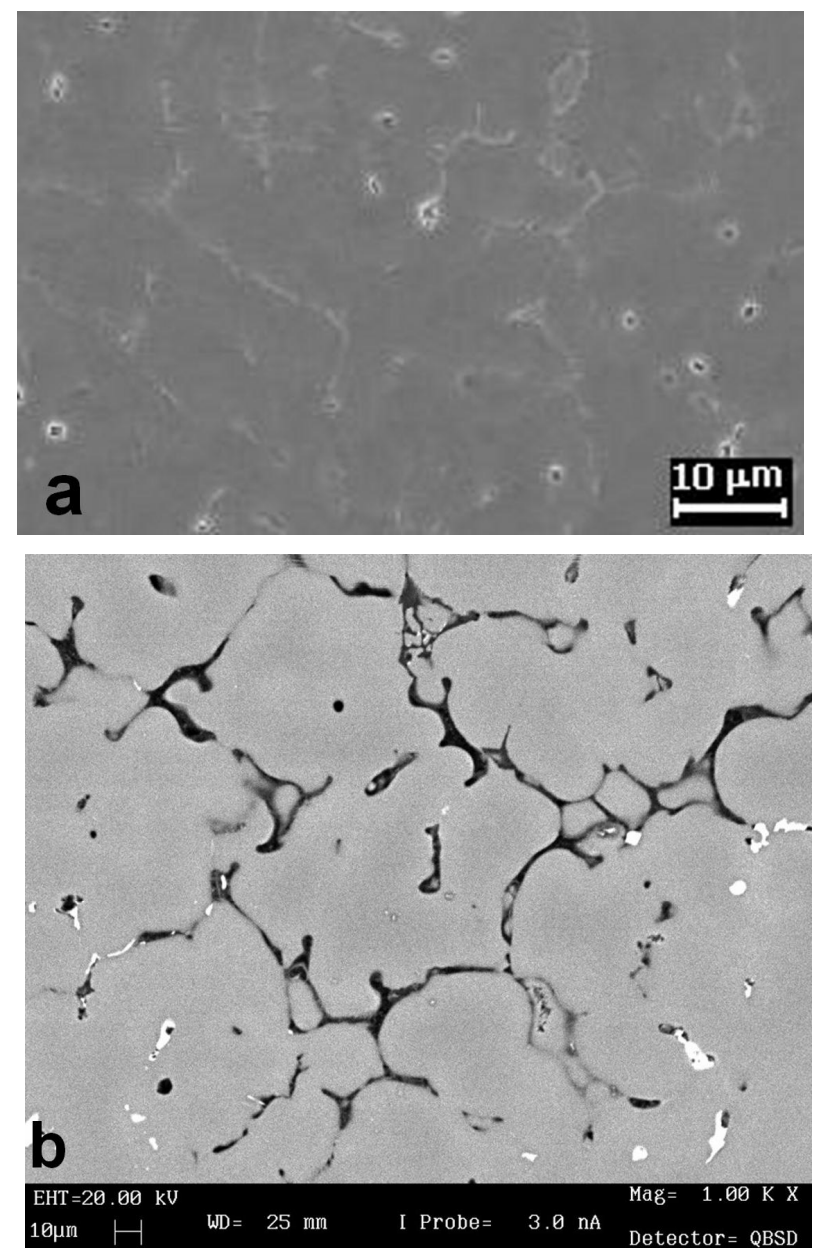

Figure 2. (a) Shows the $\alpha$-Al equiaxed dendritic microstructure from as-cast condition; (b) Interdendritic regions characteristic of microstructure in as-cast condition.

contrast corresponds to the phase $(\mathrm{MgZn})_{49} \mathrm{Al}_{32}$. While dark contrast corresponds to the $\alpha-\mathrm{Al}$ phase (Figure 3(b)), Al-matrix or solid solution rich in aluminum, possess the same FCC crystalline structure of aluminum. The literature on alloys $[9,10]$ of the type studied in this work, point out that the solidification equilibrium involves the existence of two phases. One of them is an aluminum based $\alpha$-solid solution and another phase, the $\tau$-(MgZn $)_{49} \mathrm{Al}_{32}$. The last one phase, having a variable composition around the $\mathrm{Al}_{2} \mathrm{Mg}_{3} \mathrm{Zn}_{3}$ formula, which is considered a non-stochoimetrically intermetallic phase. These intermetallic particles are the second phase that dominant the feature of $\mathrm{AlZnMn}-\mathrm{xMg}$ microstructures.

Previous work [21] has been related the magnesium content with the hardness on an Al-alloy. Evidently the hardness property is directly connected with the semicoherent and coherent precipitates rich in magnesium. The effect of coherency or semi-coherency second phase, between matrix alpha aluminium alloy is effectively to impede the dislocation motion and get a hard material. In 

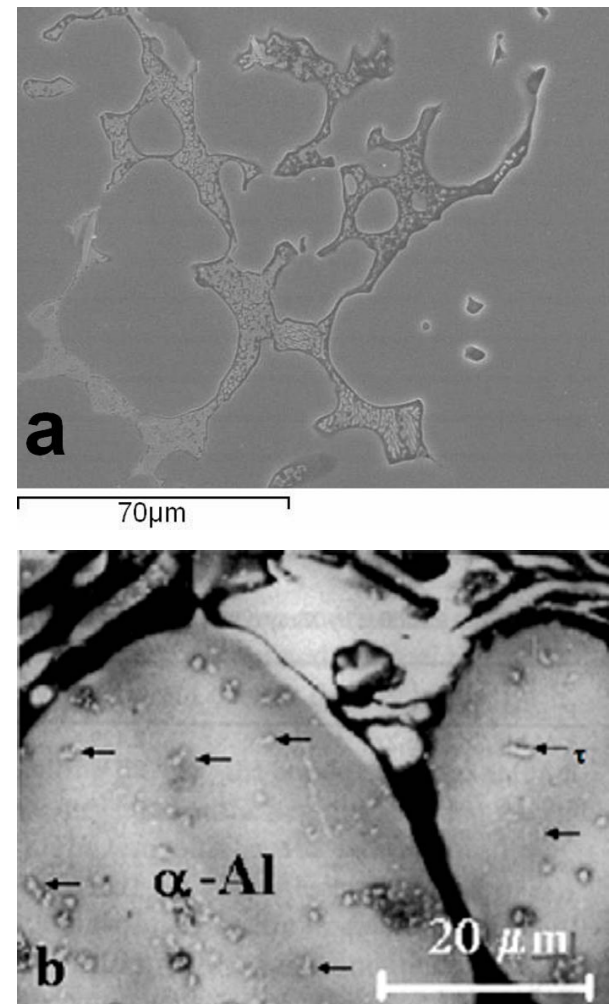

Figure 3. (a) Quasibinary eutectic of $\alpha$-Al plus (MgZn) ${ }_{49} \mathrm{Al}_{32}$ between the grain boundaries in aged alloys; (b) Detail of $\tau$ $(\mathrm{MgZn})_{49} \mathrm{Al}_{32}$ phase.

our case, the precipitate $(\mathrm{MgZn})_{49} \mathrm{Al}_{32}$ and the solid solution of the matrix alloy has the bcc and fcc crystal structure respectively. The precipitate has a different crystalline lattice spacing that the matrix material forming a connection between the hardness and crystallographic structure between these principal actors.

Another effect related could be the atomic size of alloying elements. Due to the zinc and magnesium are smaller and larger, respectively than aluminum [4]. In addition, the presence of $(\mathrm{MgZn})_{49} \mathrm{Al}_{32}$-precipitates is also associated with the galvanic efficiency. That is attributable to the difference in the electrical potential between these precipitates and the matrix. The precipitates allow a galvanic activity continued. The second phases avoiding the polarization of the alloys. The breakdown of the alumina oxide film is caused by the precipitates or second phases.

\subsection{Hardness Vickers}

Microhardness curves from the alloys in as-cast and aging condition are shown in Figure 4(a). The $\alpha$-Al structure with aging treatment is $8 \%$ harder than the surrounding Al-matrix in as-cast alloys. Indeed, the average Vickers hardness measured inside the Al-matrix for ascast structure is $83.65 \mathrm{HV}$, whereas the Al-matrix for

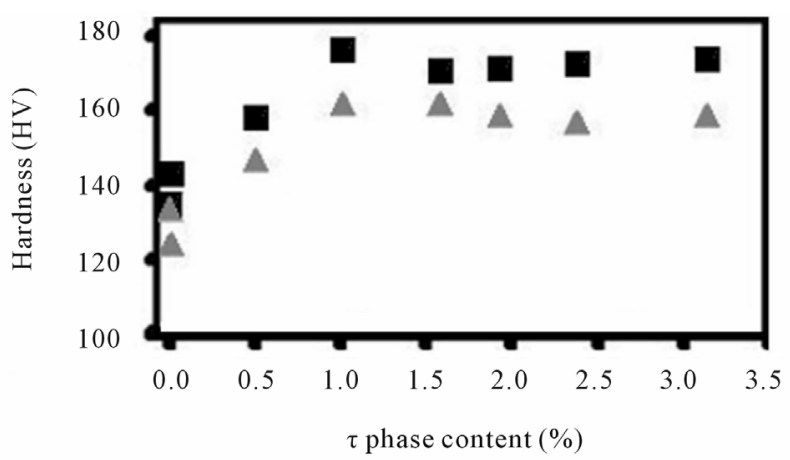

A cast condition

ageing condition

(a)

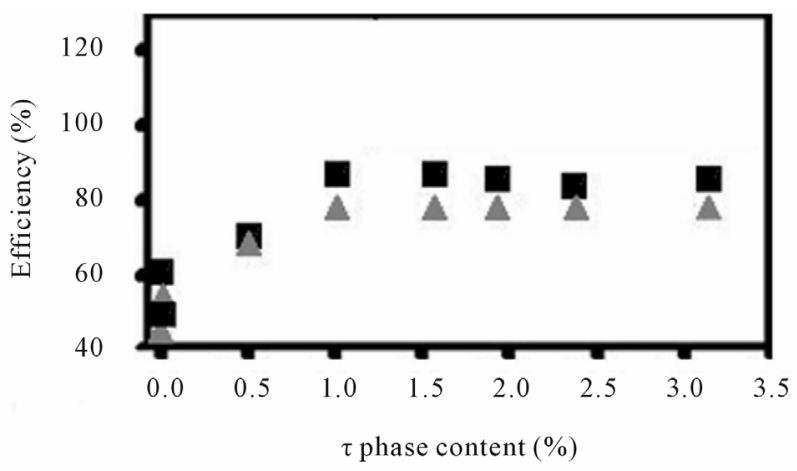

A cast condition
ageing condition

(b)

Figure 4. The hardness and anode efficiency plotted against $\tau$-(MgZn) ${ }_{49} \mathrm{Al}_{32}$ phase curves for the alloys $\mathrm{AlZnMn-xMg}$ in as-cast and aged condition.

aging is $91.81 \mathrm{HV}$. These values emphasize the influence of the $(\mathrm{MgZn})_{49} \mathrm{Al}_{32}$ particles inside the matrix. It can be seen from Figure 4 the higher point from the alloy added with $5.49 \% \mathrm{Mg}$. This alloy has a significantly hardening.

\subsection{Electrochemical Performance}

In Figure 4(b) has been showed the electrochemical performance throughout the efficiency for this alloy is developed at $1.0 \mathrm{vol} \%(\mathrm{MgZn})_{49} \mathrm{Al}_{32}$-phase particles. The peak efficiency is achieved after $4.89 \% \mathrm{Mg}$ addition. The efficiency curve for as-cast condition shows the similar behavior: the high peak is reached when $(\mathrm{MgZn})_{49} \mathrm{Al}_{32}$ phase is equal to $1.0 \mathrm{vol} \%$. It is clear that aging treatment enhances the hardness and also the efficiency, when the $\mathrm{Mg}$ addition does not exceed $5.49 \%$. It means that the phase $(\mathrm{MgZn})_{49} \mathrm{Al}_{32}$ increases due to the formation of quasi-binary eutectic structure $\left(\alpha-\mathrm{Al}+(\mathrm{MgZn})_{49} \mathrm{Al}_{32}\right)$. 
While, the $\alpha$-matrix decreases and also its distribution of $(\mathrm{MgZn})_{49} \mathrm{Al}_{32}$ precipitates.

These results emphasize that the precipitates on the matrix active the surface of the alloy. The activated surface influenced in electrochemical efficiency when it breakdown the oxide film. This passive oxide over-layer formed in air covered the surface of the $\alpha-\mathrm{AlZnMn}-\mathrm{xMg}$ alloy. The efficiency is greater when the initial attack is present for the intermetallic compounds distributed in the matrix. However, the intergranular eutectic phase begins to dissolve it and this intergranular corrosion is stronger than the $(\mathrm{MgZn})_{49} \mathrm{Al}_{32}$-phase.

\section{Conclusions}

According to the effects of magnesium addition as third alloying element on the chemical composition of AlZnMn it has been related with the microstructure and galvanic efficiency of the alloys modified with magnesium, and the following conclusions are obtained:

The precipitation of $(\mathrm{MgZn})_{49} \mathrm{Al}_{32}$ particles depends on the magnesium addition, ageing condition and the quantity of the eutectic phase formation.

The addition of $\mathrm{Mg}$ in just 5.49 at $\%$ to the ageing AlZnMn alloy clearly increases the peak efficiency as galvanic anode and generates the $1.0 \mathrm{vol} \%$ of $(\mathrm{MgZn})_{49} \mathrm{Al}_{32}$ precipitates.

For magnesium content upper than $5.49 \%$ with ageing condition the eutectic phase increases more than $(\mathrm{MgZn})_{49}$ precipitates, and the efficiency of the alloy decreases $\mathrm{Al}_{32}$ while for low magnesium content the $(\mathrm{MgZn})_{49} \mathrm{Al}_{32}$ phase is poor such as efficiency.

A galvanic efficiency performance as high as $81 \%$ has been achieved with magnesium plus aging treatment on AlZnMn-xMg alloy that activation process depends on the amount of $(\mathrm{MgZn})_{49} \mathrm{Al}_{32}$ particles deposited at the Al-matrix surface.

\section{Acknowledgements}

The authors would like to thank the UNAM-DGAPAPAPIIT IT101112-3 and CONACyT-167583.

\section{REFERENCES}

[1] T. Pervez, S. Z. Qamar, A. C. Seibi and F. K. Al-Jahwari, "Use of SET in Cased and Open Holes: Comparison between Aluminum and Steel," Materials Design, Vol. 29, No. 4, 2008, pp. 811-817.

doi:10.1016/j.matdes.2007.01.009

[2] H. K. Rafi, G. D. J. Ram, G. Phanikumar and K. P. Rao, "Microstructure and Tensile Properties of Friction Welded Aluminum Alloy AA7075-T6," Materials Design, Vol. 31, No. 5, 2010, pp. 2375-2380. doi:10.1016/j.matdes.2009.11.065

[3] S. Valdez, B. Mena, J. Genesca and J. A. Juárez-Islas,
"Evaluation of an Al-Zn-Mg-Li Alloy/Potential Candidate as Al-Sacrificial Anode," Journal Materials Engineering Performance, Vol. 10, No. 5, 2001, pp. 596-601. doi:10.1361/105994901770344755

[4] H. Sina, M. Emamya, M. Saremi, A. Keyvani, M. Mahta and J. Campbell, "The Influence of Ti and $\mathrm{Zr}$ on Electrochemical Properties of Aluminum Sacrificial Anodes," Materials Science Engineering A, Vol. 431, No. 1-2, 2006, pp. 263-276. doi:10.1016/j.msea.2006.06.011

[5] S. M. A. Shibli, "Surface Catalysis Based on Ruthenium Dioxide for Effective Activation of Aluminium Sacrificial Anodes," Corrosion Science, Vol. 46, No. 4, 2004, pp. 819-830. doi:10.1016/S0010-938X(03)00038-6

[6] F. Eckermanna, T. Suter, P. J. Uggowitzer, A. Afseth and P. Schmutz, "The Influence of MgSi Particle Reactivity and Dissolution Processes on Corrosion in Al-Mg-Si Alloys," Electrochemical Acta, Vol. 54, No. 2, 2008, pp. 844-855. doi:10.1016/j.electacta.2008.05.078

[7] G. Mrówka-Nowotnik and J. Sieniawski, "Influence of heat Treatment on the Microstructure and Mechanical Properties of 6005 and 6082 Aluminium Alloys," Journal Materials Processing Technique, Vol. 162-163, 2005, pp. 367-372. doi:10.1016/j.jmatprotec.2005.02.115

[8] F. Mondolfo, "Aluminium Alloys: Structure and Properties," Metallurgical Reviews, Vol. 16, 1971, p. 953.

[9] Z. H. Li, B. Q. Xiong, Y. A. Zhang, B. H. Zhu, F. Wang and H. W. Liu, "Investigation of Microstructural Evolution and Mechanical Properties during Two-Step Ageing Treatment at $115^{\circ} \mathrm{C}$ and $160^{\circ} \mathrm{C}$ in an $\mathrm{Al}-\mathrm{Zn}-\mathrm{Mg}-\mathrm{Cu}$ Alloy Pre-Stretched Thick Plate," Materials Characterization, Vol. 59, No. 3, 2008, pp. 278-282.

doi:10.1016/j.matchar.2007.01.006

[10] I. J. Polmear, "Light Alloys, Metallurgy of the Light Metals," 2nd Edition, Arnold, London, 1989, p. 21.

[11] G. L. Song, B. Johannesson, S. Hapugoda and D. StJohn, "Galvanic Corrosion of Magnesium Alloy AZ91D in Contact with an Aluminium Alloy, Steel and Zinc," Corrosion Science, Vol. 46, No. 4, 2004, pp. 955-977. doi:10.1016/S0010-938X(03)00190-2

[12] H. Ezuber, A. El-Houd and F. El-Shawesh, "A Study on the Corrosion Behavior of Aluminum Alloys in Seawater," Materials Design, Vol. 29, No. 4, 2008, pp. 801-805. doi:10.1016/j.matdes.2007.01.021

[13] M. Talavera, S. Valdez, J. A. Juarez-Islas, B. Mena and J. Genesca, "EIS Testing of New Aluminium Sacrificial Anode," Journal of Applied Electrochemical, Vol. 32, No. 8, 2002, pp. 807-903. doi:10.1023/A:1020547508321

[14] S. P. Ringer and K. Hono, "Microstructural Evolution and Age Hardening in Aluminium Alloys: Atom Probe FieldIon Microscopy and Transmission Electron Microscopy Studies," Materials Characterization, Vol. 44, No. 1-2, 2000, pp. 101-131. doi:10.1016/S1044-5803(99)00051-0

[15] K. Mills, J. R. Davis and J. D. Destefani, "Metallography and Microstructure," ASM Handbook, Vol. 9, 1998, p. 354.

[16] DNV Recommended Practice RP B401, "Cathodic Protection Design," Det Norske Veritas Industry As, Hovik, 1993. 
[17] ASTM D1141-98, "Standard Practice for the Preparation of Substitute Ocean Water," Annual Book of ASTM Standards, Philadelphia, 2004.

[18] G. Bergmaiv, J. L. T. Waugh and L. Pauling, "The Crystal Structure of the Metallic Phase $\operatorname{Mg}_{32}(\mathrm{~A} 1, \mathrm{Zn})_{49}$," Acta Crystallographica, Vol. 10, 1957, pp. 254-259. doi:10.1107/S0365110X57000808

[19] V. Raghavan, "Al-Mg-Zn (Aluminum-Magnesium-Zinc)," Journal of Phase Equilibria, Vol. 28, No. 2, 2007, pp. 203-208. doi:10.1007/s11669-007-9029-6
[20] B. D. Cullity, "Elements of X-Ray Diffraction," 2nd Edition, Addison-Wesley Publishing Company, Inc., Boston, 1978 .

[21] L. A. Dobrzanski, T. Tanski, J. Trzaska and L. Cizek, "Modelling of Hardness Prediction of Magnesium Alloys Using Artificial Neural Networks Applications," Journal of Achievements in Materials and Manufacturing Engineering, Vol. 26, No. 2, 2008, pp. 187-190. 